\section{Should All Pharmacists Responsible for Pharmacotherapeutic Management of Patients with Complex or Special Drug Therapy Needs Have Certification from the Board of Pharmacy Specialties?}

\section{THE "PRO" SIDE}

The American Pharmacists Association established the Board of Pharmacy Specialties in 1976, with the mission to improve patient care through recognition and promotion of specialized training, knowledge, and skills in pharmacy practice and through board certification of pharmacists. The American College of Clinical Pharmacy became involved with the process in 1989, because of its view that board certification was a necessary component of ensuring the quality of pharmacists in caring for patients. The Board currently offers certification in 6 specialty practice areas: nuclear pharmacy, nutrition support, pharmacotherapy, psychiatric pharmacy, oncology pharmacy, and the latest, ambulatory care pharmacy. Certification in each of these specialties has at its core the Board's mission to improve the quality of patients' health. The Board has begun work on pediatrics, critical care, and pain and palliative care pharmacy as potential new specialties, and has undertaken early investigation into cardiology and infectious diseases pharmacy (William Ellis, Executive Director, Board of Pharmacy Specialties, Washington, DC; personal communication, March 12, 2012).

The Board of Pharmacy Specialties has been charged with setting the standards for certification and recertification of pharmacists, as well as objectively evaluating practitioners who seek certification. Board certification is a voluntary process that confirms a pharmacist's knowledge and skill beyond what is necessary for licensure. Under consideration here is the question of whether the level of training and expertise needed to obtain board certification is necessary for all pharmacists involved in caring for patients with complex or special drug therapy needs.

But we should consider first what causes a patient to have "complex or special drug therapy needs" (an unfortunate term, as it places far too much emphasis on the drug, rather than the patient). It's not the drug therapy alone; rather, it's the concurrent medical complexity of the patient for whom the drug therapy is being applied. Yet what pharmacist performing clinical work today sees "non-complex" patients or therapies? In any area of clinical pharmacy practice, pharmacists will see "complex patients", be they patients with HIV, hepatitis C, severe heart failure, or severe depression. In turn, the care required for such patients is also complex. This enormous complexity of care mandates that all pharmacists have a broad knowledge base to be able to deal with problems as they arise.
With a virtual explosion of newly studied therapies and our expanding understanding of disease, we need some means of ensuring that the required knowledge base is there to meet the challenges of practice. I have spent my career in critical care, where all patients have complex needs, irrespective of the drugs they are receiving. However, I believe that this situation is not unique to critical care pharmacy practice. Whether you see a patient in the ICU with serotonin syndrome or a patient with rheumatoid arthritis in the pain clinic who is taking an immunomodulator, you have a "complex patient".

Our current undergraduate pharmacy education programs offer the best in knowledge and skills, but within a few short years after graduation, pharmacists find that their training has become dated. We need some way to maintain ongoing learning, with the ability to demonstrate up-to-date clinical proficiency. The alternative argument - that not everyone needs continuing training-amounts to suggesting that we should have 2 levels of pharmacists: those who can handle complexity and those who cannot! In the latter category would be found pharmacists who can only perform drug-interaction reviews, verify doses, and adjust doses for renal dysfunction. Such individuals could not reasonably suggest therapeutic alternatives or even counsel a patient on the latest therapies. But surely such a system would not benefit patients or the profession.

So, should all pharmacists practising in the clinical setting be board certified? The answer is absolutely yes. Graduation from a pharmacy program ensures only a basic level of education, whereas certification demonstrates clinical competency to both society and the profession, something that mere graduation cannot guarantee. To be sure, residency programs and fellowships can enhance clinical knowledge and skill beyond what is gained from the pharmacy degree alone, but they too are inadequate to guarantee ongoing clinical competency. Societal needs for the best care possible will not be met by a pharmacist who is not clinically current and has not demonstrated proficiency to practise. Only board certification offers these benefits.

With respect to professional needs, certification ensures competency to practise at an optimal level of care. In North America, there is currently a mix in the educational backgrounds of pharmacists working in clinical settings: some have bachelorlevel training, and others have more advanced degrees. But employers should never assume that an advanced pharmacy degree somehow ensures greater competency for clinical practice. Board certification should be and is available to all pharmacists as the one unifying factor to ensure such competency. It removes the mystery about who is able to practise at an advanced level, irrespective of educational background. This is an important point, as pharmacists have started using board certification to create an edge in the job market. ${ }^{1}$ In fact, some employers are offering pay commensurate with certification. As 
such, professional certification provides a strong incentive to keep studying and learning about a broad range of topics not otherwise offered in local educational programs, such as those offered by provincial branches of the Canadian Society of Hospital Pharmacists. Finally, certification from a professional body like the Board of Pharmacy Specialties gives practitioners an improved sense of self-worth and confidence to practise.

Many studies performed by leaders in the field have demonstrated the unique benefits to patients provided by pharmacists as members of the health care team..$^{2-5}$ The issue becomes how to capture the knowledge and skill of those pharmacy leaders and ensure that it is available to all practising pharmacists. Having our best leaders demonstrate what is possible doesn't guarantee that all pharmacists will actually be able to provide that level of expertise and skill and achieve the same beneficial outcomes of care. To answer the question of whether that level of training can be brought to the forefront of pharmacy practice through board certification, we have to review what certification involves: a 200-question specialtyspecific exam with a content outline developed by leaders in the field, covering subject matter based on a nationwide survey of the current best practices of pharmacists in that specialty area, incorporating new regulations, drugs, and therapeutic interventions. ${ }^{6}$ Recertification involves earning a minimum number of continuing education credits through Pharmacotherapy Self-Assessment Program study modules over a 7-year cycle. These modules form a comprehensive source of information for clinical practitioners. Each chapter within a study module brings the pharmacist up to date with the latest views of opinion leaders and practitioners in one particular aspect of the specialty field. Each chapter also offers at least 20 clinically based questions that challenge the reader to think of how the suggested readings can be applied to patient care. From my own experience, I have been most impressed with the annotated bibliographies within each chapter, which provide a quick review and evaluation of the key papers that have had a significant impact on practice in a particular field.

Some might argue that board certification is simply another level of training, meant only to generate money for the certifying organizations. Is there a cost? Certainly, in terms of both time and money. But are we over-training our pharmacists? I've been in critical care practice for over 24 years, and I would argue that I never feel over-trained for any of the issues that I face. Another argument against certification might be that the real world doesn't demand that level of training. In response, I would say that "you don't see what you don't know." Some have expressed concern that certification does not guarantee personal qualities such as initiative, responsibility, or a caring and collaborative attitude, ${ }^{7}$ but then again, neither does licensure. How is certification different from obtaining a certificate of training, as many continuing education programs offer for those maintaining licensure? The clear and most important distinction is that educational programs can offer an indication of participation, but only certification assesses the practitioner's competency.

Society and our profession demand that pharmacists who directly manage the care of patients meet the most rigorous expectations. Board certification is the only educational activity within pharmacy that validates practitioners in a given specialty area through rigorous examination and recertification. Do we have solid evidence that all pharmacists providing care for complex or special drug therapy patients need to be board certified? No, but it is the right thing to do!

\section{References}

1. Saseen JJ, Grady SE, Hansen LB, Hodges BM, Kovacs SJ, Martinez LD, et al. Future clinical pharmacy practitioners should be board-certified specialists. Pharmacotherapy 2006;26(12):1816-1825.

2. Bond CA, Raehl CL, Franke T. Clinical pharmacy services and hospital mortality rates. Pharmacotherapy 1999;19(5):556-564.

3. Leape LL, Cullen FJ, Clapp MD, Burdick E, Demonaco HJ, Erickson JI, et al. Pharmacist participation on physician rounds and adverse drug events in the intensive care unit. JAMA 1999;282(3):267-270.

4. Witt DM, Sadler MA, Shanahan RL, Mazzoli G, Tillman DJ. Effect of a centralized clinical pharmacy anticoagulation service on the outcomes of anticoagulation therapy. Chest 2005;127(5):1515-1522.

5. Helling DK, Nelson KM. How to develop and implement a program to continuously demonstrate the value of clinical pharmacy services. Pharmacotherapy 2000;20(10 Pt 2):340S-344S.

6. 2012 candidate's guide. Washington (DC): Board of Pharmacy Specialties; 2012 [cited 2012 May 25]. Available from: www.bpsweb.org/pdfs/ CandidatesGuide.pdf

7. Haines ST, Andrus MR, Badowski M, Bradbury MM, Canales AE, Cavanaugh JM, et al. Board certification of pharmacist specialists. Pharmacotherapy 2011;31(11):1146-1149.

Robert E Ariano, PharmD, BCPS, FCCM

Pharmacy Department

St Boniface General Hospital

Winnipeg, Manitoba

\section{THE "CON" SIDE}

Board of Pharmacy Specialties certification of all Canadian pharmacists who are responsible for the pharmacotherapeutic management of patients with complex or special drug therapy needs should not be required.

I fully support the ambitions of individual pharmacists who pursue and maintain this form of certification. There are many good reasons why they may be motivated to do so, including enhancing their patient care skills and increasing their marketability in competitive job environments. I also concur with the assertion of the American College of Clinical Pharmacy (ACCP) that certification is a "readily identifiable, objective, peer-established credential."

However, there are several practical reasons why Board of Pharmacy Specialties certification should not be required of pharmacists in Canada.

Adding another credential, such as board certification, to a clinical practice framework is viable, or even necessary, only when one or both of the following conditions exist: an adequate supply (or oversupply) of highly trained practitioners, such that further differentiation of their skills is desirable, or a recognized quality- 
or quantity-of-care deficit that the credential is known to effectively address.

Certainly the first of these 2 conditions does not apply to pharmacy in Canada at present. In fact, many Canadian jurisdictions have significant, chronic shortages of residencytrained pharmacists. We simply do not suffer from an oversupply of qualified pharmacists for complex-patient care roles. The CSHP 2015 objective that all pharmacists entering hospital practice will be residency-trained is far from being realized (the proportion was $29 \%$ in 2010), ${ }^{2}$ and major quantitative changes to the system of residency training in Canada are required before it will be achieved. Rather than providing a useful differentiating function in this environment, a requirement for board certification would be an impediment to producing complex-care specialists via residencies. Instead, it would represent another cost, another timeline, and another hurdle.

A related aside: The ACCP has made a compelling recommendation that board certification should be pursued by postgraduate year 2 (PGY2) residents during their training. ${ }^{1}$ However, Canada has no accredited PGY2 programs.

I am not aware of any published evidence that any of the available certifications from the Board of Pharmacy Specialties are directly linked to improvements in patient care by pharmacists. Such evidence would be difficult to produce, but extraordinary claims require extraordinary evidence, so proponents of the re-engineering of the Canadian credentialling system that would be prompted by a certification requirement should be required to proffer such evidence.

Since it is specifically the US system of board certification that is under discussion here, one limitation of that system should be acknowledged here. Were Canadians to adopt it as a requirement for the subset of pharmacists proposed (i.e., those providing care for complex patients), we would immediately confront the system's lack of subspecialization. For example, I doubt that the catch-all "pharmacotherapy" certification currently used for non-oncology and non-psychiatry specialist pharmacists would resonate as sufficiently meaningful or attuned to the practice environments of the large number of cardiology, critical care, infectious diseases, and pediatrics pharmacists to whom the requirement would apply. The seemingly simple solution of making more subspecialty certifications available has proved an all-but-intractable problem in the United States, ${ }^{3}$ despite that country's long history with board certification.

It is difficult to imagine how the financial burden of a requirement for board certification and recertification would be borne by individual pharmacists, given the characteristics of the
Canadian health care environment mentioned above. Unless there is a salary incentive for certification (which is difficult to envision in the unionized hospital settings of many provinces) or employers were to bear the cost by virtue of it being a job requirement (for which there is little precedent in a public health care system with limited continuing education funding for pharmacists), a certification requirement would be seen by pharmacists as arbitrary or even draconian.

Notably, even the ACCP does not endorse the requirement proposed here. The only specific population of pharmacists for which the ACCP endorses Board of Pharmacy Specialties certification is educators (i.e., preceptors and teachers) of students and residents who care for patients with complex pharmacotherapeutic needs. ${ }^{1}$ I empathize with the spirit of this approach, since, at a societal level, we expect our educators to have as many credentials as possible. Although I fear for the effects that a certification requirement for preceptors would have on our ability to deliver residency and PharmD programs in Canada, this seems the most justifiable place to start, if anywhere.

Finally, consider that "board certification is not a substitute for other credentials (e.g., professional degree, licensure, postgraduate training) and does not measure important personal qualities, such as initiative, responsibility, or a caring and collaborative attitude". ${ }^{1}$ In Canada, we have much work to do in expanding the avenues available to talented and caring pharmacists through PGY1 and PGY2 residency programs before we require unproven credentials and risk undermining those fledgling efforts.

\section{References}

1. Haines ST, Andrus MR, Badowski M, Bradbury MM, Canales AE, Cavanaugh JM, et al. Board certification of pharmacist specialists [American College of Clinical Pharmacy position statement]. Pharmacotherapy 2011;31(11):1146-1149.

2. CSHP 2015 status: goals \& objectives (May 2011). Ottawa (ON): Canadian Society of Hospital Pharmacists; 2011 [cited 2012 Mar 20]. Available from: www.cshp.ca/programs/cshp2015/docs/CSHP2015Goalsand ObjectivesStatusReportMay2011.pdf

3. Tisdale JE. An open letter to ACCP members: ACCP's board certification quandary. Lenexa (KS): American College of Clinical Pharmacy; 2010 [cited 20 Mar 2012]. Available from: www.accp.com/docs/misc/Board CertificationQuandary.pdf

Peter Loewen, BSC(Pharm), ACPR, PharmD

Lower Mainland Pharmacy Services

Faculty of Pharmaceutical Sciences

The University of British Columbia

Vancouver, British Columbia 